\title{
Rodents and Herpetofauna (Reptiles and Amphibians) as Household Pests in the Accra Metropolis, Ghana
}

\author{
F. Gbogbo, D. Attuquayefio* and A. Krobea-Asante \\ Department of Zoology, University of Ghana, P.O. Box LG 67, Legon-Accra, Ghana \\ *Corresponding author
}

\begin{abstract}
Small mammals and herpetofaunal household pests, known for their economic damages, health implications and nuisance effects on people, are frequently seen in the Ghanaian home environment. The study was aimed at assessing the relationship between the level of infrastructural development and the abundance, control methods and perception of people about rodents and herpetofaunal household pests. The results indicated that the incidence of rodents and anurans decreased with increasing infrastructural development of an area, while the occurrence of wall geckos and agama lizards was independent of the level of infrastructural development of the areas. The use of control measures, as well as the type of control measure employed, was also dependent on infrastructural development with the underdeveloped areas employing more physical and sanitary measures on daily basis, contrary to weakly and monthly bases in the developed and developing areas. Chemical control was mostly used in the developing areas while biological control was the main vertebrate pest control method in the developed areas. The level of infrastructural development of an area, therefore, gives an indication of the kind of herpetofaunal and small mammal pests likely to be prevalent in an area, and the consequences of their infestation. This information is particularly important in the choice of accommodation for rental purposes as well as town planning.
\end{abstract}

\section{Introduction}

There are as many definitions of the word "pest" as there are authors. Clark (1970) defined pests as "those injurious or nuisance species, the control of which is felt to be necessary either for economic or social reasons", and Dempster (1975) also defined a pest as "any animal which does economic damage to crops or domesticated animals, or is harmful to human health". Allaby (1999) also defined a pest as "any animal that competes with humans by consuming food, fibre or other materials for human consumption or use". Whatever definition is adopted, it is clear that an animal constitutes a pest by merely being a nuisance, or by being injurious to human health or economic well-being.

Pests are found within the whole range of animal kingdom, both vertebrate and invertebrates. Vertebrate pests generally cause damage to livestock, crops, and humans, as well as generally being a nuisance (Hubert \& Woodcock, 1983). In most households, herpetofaunal pests may include frogs (Hylarana galamensis), toads (Bufo regularis), Agama lizards (Agama agama), wall geckos Hemidactylus gamalensis and house snakes (Lamprophis sp.) Common rats (Rattus rattus) and mice (Mus musculus) constitute the rodent pests.

Anurans (frogs and toads), or tail-less amphibians, are usually considered as household pests because of their persistent croaking, particularly during their breeding season, which is a source of noise pollution (Hubert \& Woodcock, 1983), as well as their annoying presence in large numbers near buildings (Naumov, 1987). Toxic secretions from the skins of some species could be harmful to humans and domestic animals. Agama lizards and wall geckos may cause feacal contamination of uncovered water and crops during sun drying, as well as consume valuable food items. Agama lizards are known carriers of Salmonella bacteria (Madiamid, 1962), and wall geckos, apart from posing a nuisance, are thought to carry diseases which they may transfer to sleeping humans at night, even though there is no scientific evidence for this (Cansdale, 1955).

Rats and mice are unmitigated nuisance and pests that can live anywhere and eat anything (Zinsser, 1956); Microsoft Corporation, 2001). The destructiveness of rats and mice is almost unlimited (Kingdon, 1997). They are pests of agriculture and stored products, they destroy human property, and they are carriers of human diseases. They gnaw at items not only to get access to 
food supplies but also to keep their rapidly growing incisors short and sharp enough for regular use (Young, 1992). In the process, they destroy merchandise (e.g. books, leather, harnesses, gloves, cloth, fruits, vegetables, etc., both stored and in transit), cause enormous damage to buildings by gnawing wood, pipes, walls and foundation, bite holes in mail sacks and eat mail, start fires by gnawing insulation on electrical conductors, and may cause tremendous harm by consuming or spoiling grain, fruits, vegetables, nuts and eggs. They can also kill young domestic animals like fowls, and other birds, sheep and pigs by infecting them with ectoparasites (Canby, 1977), and they also transmit such diseases as the plague, salmonellosis, rat-bite fever, amoebiasis, taeniasis, etc. (Storer \& Usinger, 1957).

Accra, the capital city of Ghana, has seen a high population growth in the past few years due to natural population increase and rural-urban migration (Songsore, 1992). The effects of this increasing urban population and poverty, as reflected in inadequate housing facilities, unemployment, poorly managed community facilities and slum formation, often observed in some parts of Accra, provide suitable conditions for infestation by various herpetofaunal and rodent pests. The objectives of this study, therefore, were to investigate (i) the relationship between level of infrastructural development of communities and the prevalence or infestation levels of herpetofaunal and rodents, (ii) pest control methods employed by inhabitants of the city, and (iii) the general perception and level of awareness of inhabitants in the city about vertebrate pests in general, with regard to the health and economic implications of harbouring such pests. The study also aim at providing recommendations that would be beneficial to decision-makers, other stakeholders, and the general public, particularly in city planning, and the choice of accommodation for rental purposes.

Study area

\section{Materials and methods}

Accra has a population of approximately three million (2000 Population Census, Ghana Statistical Service). The city presents a varied landscape of modern, colonial and traditional African architecture. There are three types of settlements in the residential areas, namely:

(i) Upper class quarters, which are private housing developed by rich individuals, and are designated as developed residential areas comprising Cantonments and Lashibi. Preliminary studies involving examination of 30 houses in each study area revealed that houses in these suburbs are of high quality, with at least $97 \%$ of them well plastered, painted, ceilinged, well spaced and fenced. There were generally good sewage systems, efficient waste collection service, tarred roads and well landscaped surroundings.

(ii) Social/Low cost housing quarters, which were constructed within the framework of public programmes to provide housing for middle class people in the society, and are designated as developing residential areas comprising North Dzorwulu and Adenta Housing. About $90 \%$ of the housing were plastered, painted, ceilinged, and spaced, as indicated in the preliminary studies. Only about $47 \%$ of the housing in these areas were fenced with fewer houses having neatly kept lawns and hedges, compared to the developed areas.

(iii) Marginal shanty-town quarters, which were informally constructed housing for the generally poor-and middle income earners. These are designated underdeveloped areas, comprising Madina Zongo and Teshie, with a high incidence of informally constructed marginal housing. Preliminary studies indicated that $87 \%$ of houses in these areas were plastered and painted, $37 \%$ of which were ceilinged and $20 \%$ fenced. The buildings were generally crowded and interspersed with bare compacted soil, leaving only about $7 \%$ of the household with wellkept lawns. 


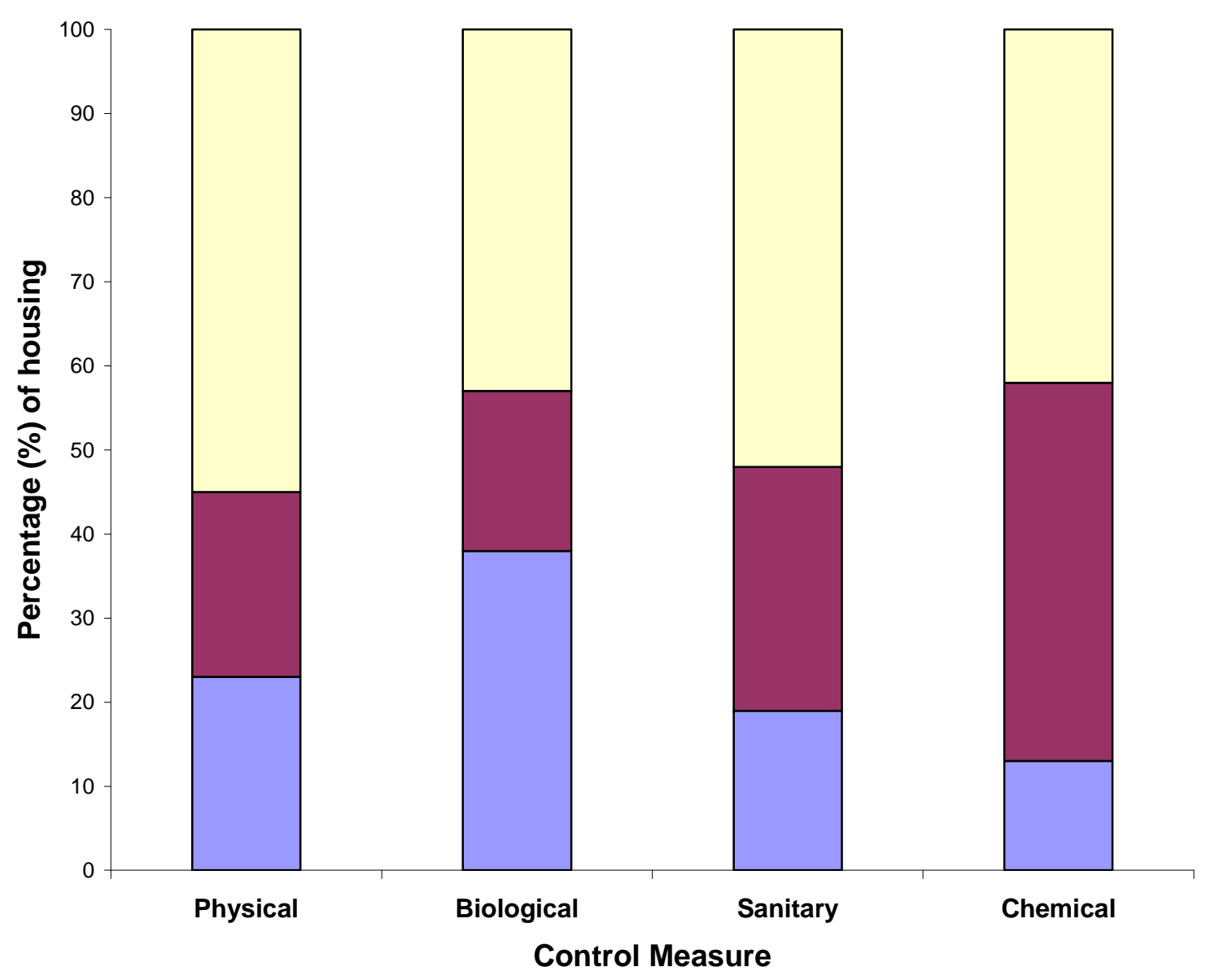

$\square$ Underdevelopeo
area
$\square$ Developingareas
$\square$ Developed area

Fig. 1. Control measures used in the selected areas

The study was, thus, undertaken in six suburbs of Accra, namely, Cantonments, Lashibi (Community 18), North Dzorwulu, Adenta (SSNIT and SHC Flats), Teshie and Madina Zongo. As indicated above, these areas were chosen based on the form and adequate suitability of certain amenities, transport network, type of settlement and other services.

\section{Lizard occurrence}

For the wall geckos, which are largely nocturnal, five exposed points in each study area with florescent lighting were selected each night at random, and the number of wall geckos observed between 6.00-7.00 p.m. over a 5-day period was recorded. For the diurnal agama lizards, any individual seen at anytime of the day was recorded. This was done in other to investigate whether the occurrence of wall geckos and agama lizards in an urban environment was dependent on the level of infrastructural development. Because of the difficulty in ensuring that no lizard was counted more than once, the frequency of occurrence of lizards, rather than absolute numbers, was determined by estimating the daily mean numbers of the lizards encountered. Any significant differences in the means (analyzed statistically using ANOVA) were expected to be linked with the level of infrastructural development.

\section{Questionnaire survey: Human-pest interactions}

A structured questionnaire was designed and pre-tested on 10 randomly-chosen individuals, and based on the results of the pre-testing, the questionnaire was restructured to include both open 
and closed questions, and administered to the inhabitants of a random sample of 180 households, (30 questionnaires per suburb). The questionnaire focused on (i) investigating the common herpetofau-nal pests and rodents often encountered in the housing, (ii) mode of interaction of these pests with the inhabitants, (iii) factors involved in the choice of common rodent and herpetofaunal control measures, rate of control and human awareness about economic and health consequences of infestation by these pests.

\section{Prevalence of herpetofauna and rodents}

\section{Results}

Agama lizards, wall geckos, frogs, toads, rats and mice occurred in all the areas, though there were some variations in the frequencies of occurrence (Table 1). More households reported seeing the agama lizards in the underdeveloped (97\%) and developing (93\%) areas than the developed areas (83\%). Similarly, the number of households which reported the presence of wall geckos increased in the order of $72 \%, 85 \%$ and $92 \%$ for the developed, developing and underdeveloped areas, respectively. Daily abundance of agama lizards, however, showed no significant difference among the developed, developing and underdeveloped areas [ANOVA, F = $0.302, P>0.05$ ] (Table 2). Similarly, the number of wall geckos recorded in the various developmental levels did not show any significant difference [ANOVA, $\mathrm{F}=0.499, P>0.05$ ) (Table 2).

TABLE 1

Occurrence of common herpetofaunal and rodent household pests (Actual figures in parentheses)

\begin{tabular}{lllll} 
Area & \multicolumn{2}{c}{ Frequency of occurrence } \\
& Agama lizards & Wall geckos & Frogs/Toads & Rats /Mice \\
Developed & & & \\
Developing & $83 \%(50)$ & $73 \%(44)$ & $60 \%(36)$ & $37 \%(22)$ \\
Underdeveloped & $93 \%(56)$ & $86 \%(52)$ & $83 \%(50)$ & $53 \%(32)$ \\
& $97 \%(58)$ & $90 \%(54)$ & $77 \%(46)$ & $77 \%(46)$
\end{tabular}

TABLE 2

Prevalence of agama lizards and wall geckos

\begin{tabular}{lrl}
$\begin{array}{l}\text { Level of infrastructural } \\
\text { development }\end{array}$ & \multicolumn{2}{c}{ Mean number/day } \\
& Agama lizards & Wall geckos \\
Developed & $9 \pm 4$ & $5 \pm 1$ \\
Developing & $12 \pm 1$ & $7 \pm 1$ \\
Underdeveloped & $13 \pm 4$ & $6 \pm 4$
\end{tabular}

When the daily abundance of wall geckos $(6 \pm 1)$ and agama lizards $(11 \pm 2)$ were compared, there was a significant difference $[t=4.90, P<0.05]$. The developing and the underdeveloped areas had significantly higher numbers of households hearing and seeing anurans around their households, compared to the developed areas [ANOVA, $\mathrm{F}=4.584, P<0.05$ ] (Table 1). Rodents were the least seen pests, and their occurrence decreased with increasing level of development [ANOVA, $\mathrm{F}=10.827, P<0.05$ ] (Table 1). Households of the underdeveloped areas reported the highest incidence of rodents around and within their houses $(77 \%)$.

Control of vertebrate household pests

About 58\% of the 180 households sampled reported using pest control measures against the common household pests. The common biological control measure reported was the use of cats as 
natural enemies of the pests. Mechanical killer traps were quite effective against the rodents, but a few of the other non-target pests were often accidentally captured. Three basic methods of chemical pest control were reported: (i) ingestion (oral), (ii) fumigation (respiratory), and (iii) dermal assimilation (skin contact). The chemicals were either mixed with food items used as bait, sprayed in closed rooms, or smeared and painted on surfaces of walls and floors, depending on the type of chemicals. Smearing or painting was the preferred method reported by $55.7 \%$ of households where control measures were used, followed by ingestion $(38.9 \%)$ and fumigation (5.4\%) methods. The common chemicals used by households in pest control are listed in Table 3.

TABLE 3

Common chemicals for the control of herpetofaunal and rodent pests

$\begin{array}{lll}\text { Pests } & \text { Brand name } & \text { Active ingredient } \\ \text { Rats and mice } & \text { Baraki } & \text { Diethialone } \\ & \text { Bromadialone } & \text { Bromadialone } \\ & \text { Black rat concentrate } & \\ & \text { Brode facoum } & \\ \text { Frogs and toads } & \text { Thiodan } & \text { Endosulfan } \\ \text { Wall geckos and agama lizards } & \text { Karate } & \text { Pyrethrin } \\ & \text { Dunsban, Pyrinex, etc. } & \text { Organosulphates } \\ & \text { Alugan spray } & \\ & \text { Kerosene } & \end{array}$

The use of pest control and frequency of use decreased with increasing level of development. Majority of the households in the developed and developing areas used pest control methods on monthly and weekly basis compared to the daily used by the majority of households in the underdeveloped areas (Table 4). Also, whereas the use of physical (trapping and mechanical crushing of pests) and sanitary control methods were highest in the underdeveloped areas, the use of chemicals in pest control was highest in the developing areas.

TABLE 4

Frequency of use of rodent and herpetofaunal control methods

\begin{tabular}{lcccc} 
Area & Use of control & \multicolumn{3}{c}{ Rate of control } \\
& & Daily & Weekly & Monthly \\
& & & & \\
Developed & $40 \%$ & $5 \%$ & $23 \%$ & $12 \%$ \\
Developing & $53 \%$ & $4 \%$ & $27 \%$ & $22 \%$ \\
Underdeveloped & $80 \%$ & $43 \%$ & $29 \%$ & $8 \%$
\end{tabular}

Discussion

Prevalence of rodents and herpetofauna

From the results, it appeared that the occurrence of wall geckos and agama lizards is not dependent on the infrastructural development of an area. One reason may be that lizards often take advantage of the opportunities offered by human settlements, with their large numbers of insects. The availability of light sources in houses attracts insects, which in turn attract wall geckos, which are nocturnal and generally insectivorous (Naumov, 1987). Since most houses in the city, irrespective of level of development, have good lighting systems, the prevalence of wall geckos was not expected to be dependent on the level of development. 
The significant difference in daily abundance between wall geckos and agama lizards, as observed in this study, suggests that the abundance of the two species of lizards in households is affected by different factors. One possible factor is a difference in fecundity, which determines the number of eggs laid, and, consequently, the number of offspring produced. Wall geckos are known to produce two eggs at a time, while agama lizards may lay three or more (Cansdale, 1955). Another factor may be behavioural. Wall geckos, being nocturnal and frequently occurring indoors, are more likely to be affected by the activities and beliefs of human beings, which may result in their being killed on sight. Agama lizards, which are diurnal and occur mostly outdoors, are under less pressure from human activities, and, therefore, face less risk of being killed. Also agama lizards are more conspicuous and gregarious in nature, while wall geckos are more secretive, making them more difficult to observe (Cansdale, 1955).

As the results indicated, more anurans were heard or seen in the developing and underdeveloped areas than the developed areas. This finding may be related to the fact that there were more constructional projects at various stages of development in the less-developed areas. Such on-going projects provide suitable habitats such as uncovered drains, dug holes, scattered construction materials and equipment, which collect water after heavy rains and provide suitable breeding and hiding places for the anurans.

Rodents are known to thrive under insanitary conditions in urban areas, so their higher occurrence in the less-developed suburbs is expected. Factors that engender insanitary conditions in such areas are bad refuse disposal practices, high population growth rates, overcrowding and poverty, among others. For example, in the underdeveloped areas, lack of sufficient financial resources forces some inhabitants to undertake small-scale commercial activities such as operating local restaurants (chop bars) and grain milling in their residences. Such activities attract the rodents, which are very prolific and, therefore, multiply rapidly. The occurrence of rodents in the developing areas may be due to inefficient sewage and waste disposal systems. In the developed areas, the rodents mainly occurred in households adjoining undeveloped plots of land, which people occasionally used as refuse dumps.

\section{Control of vertebrate household pests}

As the results indicated, chemical control was most used in the developing areas. This could be explained by the fact that the low prevalence of pests in the developed areas was not worth the risks involved with the use of some of the chemicals. In the underdeveloped areas, however, cost may be the main deciding factor, because of the level of poverty in such areas. Obviously, level of development influences the choice of pest control measure.

Sanitary control measures were the most common pest control methods reported to be practiced against all the pests. This should be expected, since it is practically inexpensive, and only required changes in perceptions, attitudes and behaviours of the inhabitants. Such measures included proper waste disposal, and practicing personal hygiene (e.g. covering of food and water), and keeping clean surroundings. Level of development influenced the use of sanitary control measures, as the availability of certain amenities such as refrigerators, storage cupboards, and efficient public waste disposal systems collection scheme reduce the amount of individual effort required for efficient sanitary control.

\section{Perceptions about vertebrate household pests}

From the results, it appeared that the inhabitants were most concerned about the presence or rodents, due to the unlimited damage they are capable of causing, which always ends up in some form of financial loss, apart from the health risks (food poisoning, disease transmission) posed to people who come into contact with them. Wall geckos also cause much concern because of their close proximity to humans. It is generally believed that they are of both spiritual and medical importance. Apart from their perceived ability to attract evil spirits to households, they are also thought to be the souls of buildings, which may collapse if a gecko is killed. There is also the 
belief that they cause skin rashes, irritation, blisters or sores when they crawl on the skin of sleeping people, particularly around the mouth. There is, however, no evidence in the available literature that wall geckos are associated with disease transmission, either as causal agents or vectors (Cansdale, 1955; Bellairs, 1957), even though the possibility may exist.

There was not much concern about the occurrence of agama lizards around households, probably because they are mostly outdoors, and there is no known human disease associated with them. There was, however, some concern expressed about the presence of anurans because they were generally considered a nuisance due to their noisy nature, and the erroneous belief that they can bite under great provocation. It should be noted that the presence of some of these pests in households may serve to attract more dangerous animals. For example, anurans and rodents are the preferred food of snakes which may frequent households with high infestations of these pests. On the other hand, sight should not be lost of the fact that some of these pests serve useful purposes in households. Lizards, especially wall geckos, and anurans are important biological control agents for all kinds of insects occurring in households.

\section{Conclusion and recommendations}

Small mammal and herpetofaunal pests occur in urban areas, irrespective of infrastructural development, but generally, their prevalence tended to decrease with increasing levels of development. In the case of anurans, this trend may be attributable to the relatively higher frequency of abandoned construction dug-outs and water reservoirs which become filled up during the rainy season.

The level of infrastructural development was also related to the type of vertebrate pest control measures employed, as well as the frequency of application of the control measures. The underdeveloped areas used more physical and sanitary control measures on a daily basis, while the use of chemical control on weekly or monthly basis was more common in the developing areas. In the developed areas there was limited pest control because of generally adequate storage and disposal facilities and good sanitation. Since contamination from the droppings of these pests could have public health consequences, it is recommended that water that is stored for domestic purposes is adequately covered to prevent the pests themselves or their droppings from falling into the containers or reservoirs. There should also be proper disposal of both liquid and solid waste, as well as proper siting of mechanical workshops, industrial establishments, etc. that generate a lot of waste. It is also recommended that periodic education and awareness campaigns should be organized by the city authorities to sensitize the inhabitants on the health and economic consequences of environmental neglect.

\section{Acknowledgement}

The authors extend their sincere appreciation to the inhabitants of Cantonments, Lashibi, Madina, Adenta, North Dzorwulu, and Teshie for sharing their time and knowledge. Special thanks also go to Mr O.M. Nyampong, Miss N.Y. Saah-Poku, Mr D. Kattah, and Mr M. Osae for their contributions in diverse ways towards the success of this work.

\section{References}

Allaby M. (1999). Dictionary of Zoology. Oxford University Press, Oxford.

Bellairs A. (1957). Reptiles, 2nd edn. Hutchinson \& Co., London.

Canby T. Y. (1977). The rat: lapdog of the devil. In Microsoft Encarta Encyclopaedia Deluxe (2001). Microsoft Corporation.

Cansdale G. S. (1955). Reptiles of West Africa. Penguin Books, London.

Clark L. R. (1970). Analysis of pest situations through the life system approach. In Concepts of Pest Management (R. L. Robb and E. F. Guthrie, ed.) North Carolina State University, North Carolina.

Dempster J. P. (1975). Animal Population Ecology. Academic Press, London.

Hubert M. and Woodcock D. (1983). The Scientific Principles of Crop Protection. Thomson Litho., Scotland. 
Kingdon J. (1997). The Kingdom Field Guide to African Mammals. Academic Press/Harcourt Brace, San Diego. Madiamid A. (1962). Diseases of Free-living Wild Animals. FAO Agricultural Studies, Rome.

Microsoft Corporation (2001). Rodents. Microsoft Encarta Encyclopaedia Deluxe.

Naumov D. (1987). Zoology, Textbook for Schools. Mir Publishers, Moscow.

Songsore J. (1992). Review of Household Environmental Problems in the Accra Metropolitan Area, Ghana. Stockholm Environmental Institute, Stockholm.

Storer T. I. and Usinger R. L. (1957). General Zoology. McGraw-Hill, New York.

Young J. Z. (1992). The Life of Vertebrates. Oxford University Press, Oxford.

Zinsser H. (1956). Rats, Lice and History: A Study in Biography. Little Brown and Company, Boston, USA. 